\title{
As dificuldades relacionadas à interpretação da linguagem algébrica no $8^{\circ}$ ano
}

\section{Difficulties related to the interpretation of algebraic language in grade 8}

\author{
Raimundo Gomes de Souza ${ }^{1 *}$, Elim de Almeida Rodrigues ${ }^{2}$, Jucely Silva de Andrade 3
}

\begin{abstract}
RESUMO
Essa pesquisa foi desenvolvida, afim de contribuir para o ensino e a aprendizagem da álgebra no $8^{\circ}$ ano do ensino fundamental. Nosso objetivo foi identificar e analisar as dificuldades enfrentadas pelos alunos do $8^{\circ}$ ano, em relação á linguagem algébrica. Nessa pesquisa tivemos como sujeitos os alunos de uma turma do $8^{\circ}$ ano do ensino fundamental, de uma escola localizada no município de Abaetetua/Pa. Foi dividida em três etapas, onde na primeira fez-se um levantamento bibliográfico do surgimento da álgebra e das possíveis dificuldades enfrentadas pelos alunos relacionados à linguagem algébrica; na segunda etapa foi aplicado, aos sujeitos da pesquisa, um teste com seis questões envolvendo equações do $1^{\circ}$ grau e por fim foi feita a análise dos registros dos alunos, as quais foram separadas em quatro categorias: não usaram incógnitas para resolver as questões; dificuldades no uso de incógnitas; dificuldades na interpretação dos problemas propostos; dificuldade no cálculo operacional aritmético. Além dessas categorias, alguns registros dos alunos foram analisados separadamente peculiaridades na resolução.
\end{abstract}

Palavras-chave: Linguagem matemática; Interpretação da linguagem algébrica; Aprendizagem.

\begin{abstract}
This survey was developed in order to contribute to the teaching and learning of algebra in the 8th grade of elementary school. Our goal was to identify and analyze the difficulties faced by students of grade 8 , in relation to algebraic language. In this research we had students as subjects of a class of 8th grade of elementary school, a school located in the city of Abaetetuba / PA. It was divided into three stages, where the first made up a literature of the emergence of algebra and the possible difficulties faced by students related to algebraic language, the second step was applied to the research subjects, a test with six questions involving equations 1 st degree and was finally made an analysis of student records, which were separated into four categories: no unknowns used to resolve the issues, difficulties in the use of unknowns; difficulties in interpreting the proposed problems, difficulty in calculating operating arithmetic. In addition to these categories, some student records were analyzed separately because they have peculiarities in the resolution.
\end{abstract}

Keywords: Language Mathematics. Algebraic Interpretation of Language. Learning.

\footnotetext{
${ }^{1}$ Universidade de Passo Fundo. *E-mail: raymestrexatas@gmail.com

${ }^{2}$ Secretaria de Estado de Educação do Pará.

${ }^{3}$ Secretaria Municipal de Educação de Abaetetuba/PA.
} 


\section{INTRODUÇÃO}

O presente escrito é resultado de uma pesquisa que foi desenvolvida afim de contribuir para com o ensino e a aprendizagem da álgebra no $8^{\circ}$ Ano do Ensino Fundamental. Esta foi provocada pela inquietação ocorrida no estágio supervisionado quando se percebeu as dificuldades enfrentadas pelos alunos referente ao ensino e aprendizagem da álgebra. Assim, nosso objetivo foi identificar e analisar as dificuldades enfrentadas pelos alunos em relação a linguagem algébrica. Diante disso, buscamos estudar autores que problematizam o ensino da álgebra e identificam as possíveis dificuldades que os alunos enfrentam na resolução de problemas matemáticos, seja na interpretação, na tradução dos problemas da linguagem natural para a linguagem algébrica, bem como, na resolução de equações algébricas.

A relevância da pesquisa em Álgebra deve-se entre outros pontos a importância que o ensino e a aprendizagem da álgebra ocupam na Matemática escolar e a dificuldade que os alunos do $8^{\circ}$ Ano apresentam neste eixo temático ainda em pleno século XXI. Logo, é um tema importante a ser discutido e buscar identificar as causas dessa dificuldade apresentada pelos alunos e ao mesmo tempo propor situações que possam vir a sanar essas dificuldades.

Quanto à linguagem matemática, fundamental para a construção do conhecimento, esta precisa produzir significados, pois, se não for significativa, não tiver relação com o contexto sócio cultural do aluno, muito provavelmente cairá no esquecimento. Entendemos que a matemática, tem sido apresentada de forma descontextualizada, utilizando-se métodos tradicionais de ensino como poucos subsídios para que o aluno desenvolva uma compreensão da realidade. O formalismo encontrado na linguagem matemática muitas vezes dificulta o entendimento do aluno fazendo com que este apresente certa “aversão" à matemática.

Com relação ao ensino da álgebra percebemos que os alunos apresentam muitas dificuldades, com isso, entendemos que é fundamental que o professor conheça métodos atuais que facilitem o entendimento dos alunos nessa área da matemática, possibilitandoo falar ou descrever um problema utilizando-se da linguagem algébrica. Diante disso, elaboramos este trabalho o qual foi realizado através de uma pesquisa qualitativa, 
observando e analisando as dificuldades encontradas na aprendizagem de Álgebra e as suas possíveis razões.

\section{DIFICULDADE DE APRENDIZAGEM NA ÁLGEBRA}

A Álgebra é significativa enquanto estratégia na resolução de problemas, pois ajuda a melhorar a compreensão e a desenvolver o raciocínio lógico matemático, contribuindo para um pensamento autônomo e permitindo assim que o aluno possa equacionar e resolver problemas de situações do cotidiano. Entretanto, apesar de a Álgebra constituir um espaço bastante significativo de abstração e generalização, além de possibilitar a aquisição de uma poderosa ferramenta para resolver problemas, este apresenta dificuldades relativas ao fazer pedagógico com a linguagem algébrica e em cálculos algébricos realizados que impossibilitam que os alunos compreendam os conceitos associados.

De acordo com Lima e Vilhena (2010) o método tradicional de ensino tão evidente nas escolas públicas de ensino, demostra claramente ineficácia no processo de aprendizagem nessa disciplina quando os alunos ingressam no $8^{\circ}$ ano. Com isso, a escola tem ficado à espera que a construção do conhecimento aconteça pela repetição, reprodução ou,

[...] memorização das técnicas e a busca de modelos facilitadores, onde o aluno diante de um problema tem apenas duas alternativas de ação: ou ele reconhece um modelo ou fórmula a ser empregado ou, então, só lhe resta desistir, esperando a solução do professor ou a nota baixa (DINIZ, 1991, p. 29).

A Álgebra trabalhada em sala de aula, como um estudo de manipulações roteirizadas, tem contribuído para muitos insucessos, fortalecendo a ideia de que a matemática é algo abstrata, mecanizada e descontextualizada. Os alunos têm dificuldades em compreender procedimentos que fazem parte do estudo algébrico.

Sendo assim, compartilhamos das ideias de Gil (2008) quando infere que, para construir conceitos e se apropriar de forma efetiva dos procedimentos algébricos, é fundamental que o educando consiga produzir significados para o seu estudo. No entanto, percebe-se que o trabalho com o estudo algébrico não produz a eficácia esperada na aprendizagem dos alunos devido este não ir além de manipulações de símbolos, na maioria das vezes não possuem nenhum significado, e o seu estudo desenvolvido de forma mecânica e descontextualizada. 
As dificuldades dos alunos do $8^{\circ}$ ano, no que diz respeito à aprendizagem da Álgebra, podem estar relacionadas com o fato da recusa em aceitar uma letra representando número desconhecido e não perceber o sentido de uma expressão algébrica. Além do mais apresentam dificuldades na interpretação dos problemas matemáticos propostos, e na tradução dos mesmos da linguagem comum para a linguagem simbólica da Álgebra.

Neste sentido, concordamos com Ponte, Branco e Matos (2009), quando afirmam que as dificuldades dos alunos na tradução de situações dadas em linguagem natural para sistemas de equações são em grande medida idênticas às que apresentam em casos que conduzem a outros tipos de condições. Essas dificuldades têm múltiplas origens que vão desde a falta de compreensão dos enunciados em linguagem natural, o desconhecimento das regras de sintaxe da linguagem algébrica, o estabelecimento de relações incorretas entre as duas linguagens, bem como, a simples distração ou o foco em pistas enganadoras.

A interpretação da linguagem simbólica é um dos fatores que contribuem para que os alunos apresentem certa dificuldade no aprendizado da Álgebra, pois tal linguagem exige do aluno certo grau de abstração que o mesmo pode não ter desenvolvido nas séries anteriores. Sendo assim, compartilhamos das ideias de Zuchi (2004) quando afirma que:

\begin{abstract}
"Muitas vezes, o excesso de simbologia gera dificuldades desnecessárias para o aluno, chegando inclusive a impedir que ele compreenda a ideia representada pelo símbolo e num sentido mais amplo, pode acabar impossibilitando a aprendizagem, uma vez que, sem fluência na linguagem matemática, ampliam-se as dificuldades do destinatário em entender a mensagem" (ZUCHI, 2004, p.51).
\end{abstract}

Outro fator que pode contribuir para as dificuldades dos alunos em relação ao ensino e a aprendizagem da Álgebra é a metodologia utilizada pelo professor, pois percebe-se que muitas vezes o ensino de Álgebra é apresentado para o aluno de forma mecanizada, descontextualizada e rotineira. Sendo assim, ao se trabalhar os conceitos e procedimentos algébricos sem uma metodologia adequada, dificulta-se a aprendizagem dos alunos. Logo, é fundamental que o professor conheça métodos que facilitem o ensino dessa temática e não leve a uma "técnica repetitiva" de um "simbolismo extremado", com vista ao desenvolvimento do pensamento algébrico dos alunos. Incentivar o aluno a falar ou descrever o problema pode ser uma ponte para o simbolismo algébrico, o entendimento e a resolução do problema. 
Das observações feitas durante o estágio no ensino fundamental, percebemos momentos de frustração dos alunos que não conseguiam alcançar um desempenho satisfatório nas aulas de matemática. Estas frustrações dos alunos ocorriam entre outros fatos porque na maioria das vezes não entendiam a necessidade do aprendizado de Matemática, bem como, não percebiam a significância dos assuntos matemáticos oportunizados pelo professor. Assim, segundo os PCNs de matemática, no ensino fundamental:

\begin{abstract}
"Os adolescentes desenvolvem de forma significativa a habilidade de pensar "abstratamente", se lhes forem proporcionadas experiências variadas envolvendo noções algébricas, a partir dos ciclos iniciais, de modo informal, em um trabalho articulado com a aritmética. Assim, os alunos adquirem base para uma aprendizagem de Álgebra mais sólida e rica em significados" (BRASIL, 1997, p.117).
\end{abstract}

Portanto, entende-se que a linguagem é fundamental para a construção do conhecimento e precisa produzir significados, pois, se não for significativa, não tiver relação com nada na vida do aluno, muito provavelmente cairá no esquecimento. Com isso, se faz necessário propiciarmos momentos para que nossos alunos explicitem as suas formas de raciocínio.

Cabe ao professor explorar as diferentes expressões da linguagem matemática, como oral, escrita, a visual e não só a simbólica, visando diminuir as distâncias da matemática de sala de aula e a vivencia do dia a dia. $\mathrm{O}$ trabalho mediado pelo professor em sala de aula no ensino de matemática deve priorizar as práticas metodológicas que apontem para uma relação mais estreita com a língua materna para que os alunos possam ter suporte e sintam-se seguros para atingir os níveis de abstração necessários para o conhecimento matemático.

\title{
PESQUISA E ANÁLISE DE DADOS
}

Esta pesquisa caracteriza-se como uma pesquisa de campo, que segundo Fiorentini e Lorenzato:

É aquela modalidade de investigação na qual a coleta de dados é realizada diretamente no local em que o problema ou fenômeno acontece e pode se dar por amostragem, entrevista, observação participante, pesquisa-ação, aplicação de questionário, teste, entre outros (FIORENTINI e LORENZATO, 2006, p. 106). 
A pesquisa foi realizada em uma escola pública localizada no município de Abaetetuba/PA, turma do $8^{\circ}$ Ano. Participaram deste estudo 26 alunos, identificados por letras de (A - Z). Utilizou-se a metodologia da Análise de erro como abordagem de pesquisa. Considerando esta abordagem, a análise das repostas dos alunos investigados, foi realizada inicialmente como uma categorização, agrupando-as em quatro categorias: Não usaram incógnitas para resolver as questões; Dificuldades no uso de incógnitas; Dificuldades na interpretação dos problemas propostos; Dificuldade no cálculo operacional aritmético.

A análise dos dados por meio de categorias foi baseada nos escritos de Patrício (2010), método utilizado para analisar registros dos dados coletados em suas pesquisas. Em seguida, é descrito cada tipo de erro e suas possíveis causas. A análise das questões foi abordada de forma qualitativa, onde foram observados não somente os acertos dos alunos, mas suas dificuldades na resolução das questões, bem como, dos métodos que eles utilizaram para resolvê-las.

O instrumento de coleta de dados foi um teste com 6 questões envolvendo conteúdos relativos à equação do primeiro grau. Este instrumento objetivou verificar o conhecimento adquirido e a capacidade de abstração dos alunos, as dificuldades encontradas no uso de incógnitas para representar um valor desconhecido e na interpretação dos problemas propostos.

A escolha por questões algébricas deve-se ao fato desta ser oportunizada mecanicamente pela maioria dos professores, deixando com isso de ser um instrumento capaz de desenvolver um raciocínio abstrato nos alunos. Isso porque para resolver um problema matemático, é preciso traduzi-lo para a linguagem matemática a situação descrita no enunciado. Assim, recorre-se a Álgebra simbolizando as quantidades desconhecidas por letras e construindo sentenças com os sinais apropriados. Nessa tradução, muitas vezes escrevemos sentenças abertas que expressam igualdade, e equacionamos o problema, criando uma equação que nos ajudará chegar a uma solução. O conceito de equações exige a compreensão do significado do sinal de igual e do número desconhecido. "Equação é uma sentença matemática aberta expressa por uma igualdade" (BONJORNO, BONJORNO e OLIVARES, 2006, p. 140).

Uma concepção das equações é que se trata de calcular com letras e que podem ter uma interpretação prática. Os cálculos algébricos dependem da correta manipulação dos símbolos e das operações. "Essa é a perspectiva que estabelece, definitivamente, 
nossa afirmação de que a atividade algébrica e a atividade aritmética acontecem juntas, embora em planos diferentes" (LINS e GIMENES, 1997, p. 122). As atividades algébricas e aritméticas não só podem como devem ser desenvolvidas juntas desde as primeiras séries do Ensino Fundamental.

Outra abordagem é o método de equações equivalentes que consiste em efetuar a mesma operação nos dois membros, ou por meio do princípio aditivo (que consiste em adicionar um número oposto ao termo independente em ambos os membros da equação, no sentido de isolar a incógnita em um dos membros da igualdade, mantendo assim a equação equivalente) ou por meio do princípio multiplicativo (o qual consiste em multiplicar os dois membros da equação por um número inverso ao termo que multiplica a incógnita, no sentido de isolar a incógnita em um dos membros da igualdade, mantendo assim a equação em equilíbrio). Pode-se ainda utilizar-se da substituição de uma equação em outra para encontrar o valor desconhecido.

Os problemas do teste foram extraídos de livros didáticos do $7^{\circ}$ e do $8^{\circ}$ ano do Ensino Fundamental. As obras consultadas foram: "Matemática, fazendo a diferença", de José Roberto Bonjorno, Regina Azenha Bonjorno e Ayrton Olivares (2006); e "A conquista da matemática” de José Ruy Giovanni Júnior e Benedicto Castrucci (2009).

\section{DESCRIÇÃO E ANÁLISE DOS REGISTROS DOS ALUNOS}

A seguir apresentamos os registros das resoluções feitas pelos alunos segundo cada categoria, e faremos nossas considerações sobre cada um desses registros.

\section{Categoria 1: Não usaram incógnitas para resolver as questões}

Os alunos não usaram as incógnitas para resolver as questões pela dificuldade em aceitar uma letra para representar um valor desconhecido e por não identificarem o sentido de uma expressão algébrica. De fato, percebe-se que no momento em que há a introdução da Álgebra no ensino de matemática, quando as letras passam a representar números, o aluno passa a não compreender esse universo simbólico oferecendo certa resistência ao uso dessas letras, pois até então estava acostumado a trabalhar apenas com números e, além disso, o professor não apresenta a ideia que esses símbolos representam.

Os alunos não usaram as incógnitas para resolver as questões pela dificuldade em aceitar uma letra para representar um valor desconhecido e por não identificarem o 
sentido de uma expressão algébrica. No momento em que há a introdução da Álgebra no ensino de matemática, quando as letras passam a representar números, o aluno passa a não compreender esse universo simbólico e oferece resistência ao uso dessas letras, pois estava acostumado a trabalhar apenas com números e, além disso, o professor não apresenta a ideia que esses símbolos representam.

Diante disso observa-se que os alunos usaram apenas a aritmética para resolver as questões, no entanto, os mesmos conseguiram interpretar os enunciados das questões, e mesmo não traduzindo para a linguagem algébrica na forma de equação, conseguiram chegar ao resultado "correto", haja visto que as questões dessa categoria foram consideradas de nível "fácil" exigindo poucos cálculos. Categoria observada com frequência nas questões 1 e 2.

Enunciado do teste:

Questão 1: Recebi um aumento de $R \$ 30,00$ e passei a ganhar $R \$ 270,00$. Qual era o meu salário?

Veremos agora a figura da resolução do aluno A para a $1^{\text {a }}$ questão.

Imagem 1: Resposta do aluno A à questão 1.

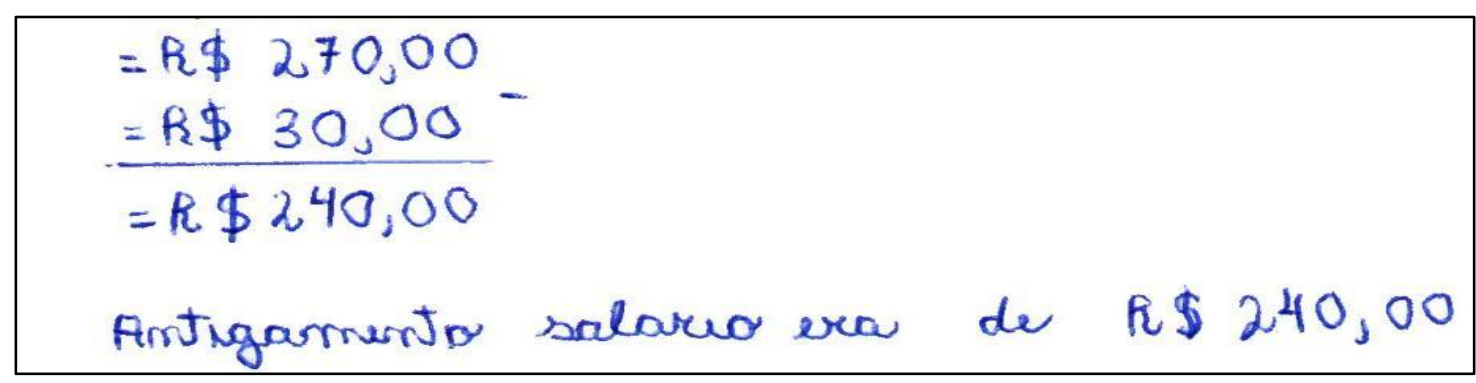

Fonte: Pesquisa de campo / Atividade didática (2012)

Neste registro observou-se que o aluno "conseguiu" resolver a questão, usando apenas o cálculo aritmético. Ele conseguiu interpretar de "forma correta" o enunciado da questão, no entanto, não traduziu para a linguagem algébrica e não se utilizou de incógnitas para representar o valor desconhecido. Diante disso, reforçamos a ideia de que o aluno apresenta certa resistência em aceitar o uso de letras para representar um valor desconhecido.

Com isso, compartilhamos das ideias de Gil (2008) quando afirma que além da tradução de um problema real para a linguagem algébrica, a resolução de um problema exige que o aluno utilize os conhecimentos que fazem parte dos procedimentos algébricos. Esta nova fase, que tem início no $7^{\circ}$ ano e aprofunda-se no $8^{\circ}$ ano, em que o aluno se depara com um cenário totalmente novo e algumas vezes esses procedimentos 
são contraditórios aos dos procedimentos aritméticos, aos quais estava acostumado, também é um fator que gera grandes dificuldades.

Enunciado do teste.

Questão 2: Dona Iracema comprou 6 pacotes de detergente em pó e um litro de água sanitária. Ao todo ela gastou 100 reais, sendo que pela água ela pagou 4 reais. Qual o preço de cada pacote de detergente?

A seguir, veremos a figura da resolução do aluno Y para a $2^{\mathrm{a}}$ questão.

Imagem 2: Resposta do aluno Y à questão 2.



Fonte: Pesquisa de campo / Atividade didática (2012)

Assim como no registro anterior, percebeu-se que esse aluno conseguiu interpretar o enunciado da questão e chegar ao resultado "correto", porém não traduziu para a linguagem algébrica e não se utilizou de incógnitas para representar o valor desconhecido. O aluno poderia ter montado a equação $6 x+4=100$, e resolver usando o princípio aditivo e multiplicativo.

Verifica-se que tanto o aluno A quanto o aluno Y chegaram ao resultado "correto" mesmo não utilizando incógnitas para resolver a questão. Infere-se que isso ocorreu pela questão ser considerada de nível fácil, sendo assim, utilizaram-se de outro método para resolver.

\section{Categoria 2: Dificuldades no uso de incógnitas}

Nessa categoria, os alunos identificaram ser preciso fazer uso de incógnitas para resolver a questão, contudo, não conseguiram utilizá-las como linguagem auxiliar na resolução das questões. Acredita-se que isso acontece devido os alunos ainda não terem conseguido fazer uso adequado dessa linguagem e, assim traduzir tais problemas para a linguagem algébrica na forma de equação, pois os mesmos não associaram "corretamente" os números com as incógnitas. Isso reforça a ideia de que os alunos do $8^{\circ}$ ano apresentam dificuldades na compreensão e na tradução da linguagem algébrica. Essa categoria foi observada nas questões 1 e 3 . 
Enunciado do teste.

Questão 1: Recebi um aumento de $R \$ 30,00$ e passei a ganhar $R \$ 270,00$. Qual era o meu słlákiguîr, veremos a figura da resolução do aluno $\mathrm{P}$ para a $1^{\mathrm{a}}$ questão.

Imagem 3: Resposta do aluno $P$ à questão 1.

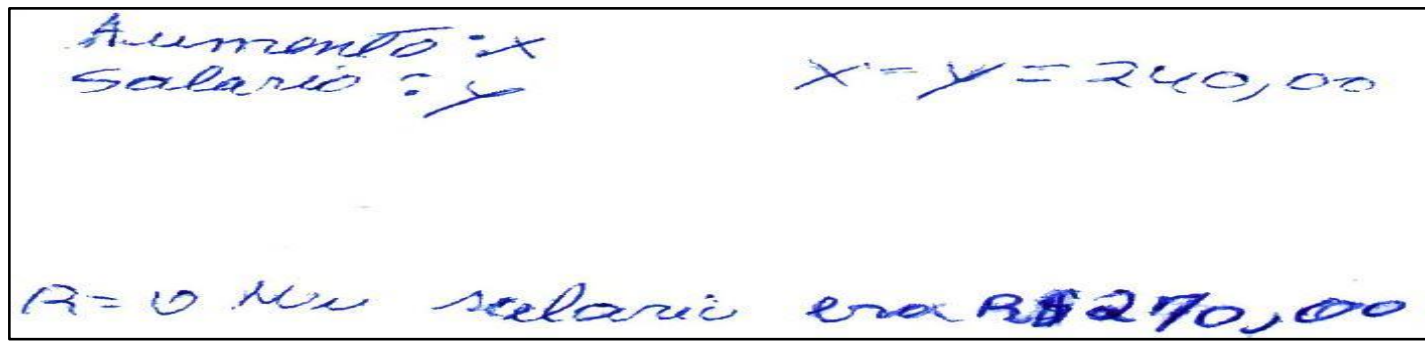

Fonte: Pesquisa de campo / Atividade didática (2012)

Nesse registro, percebe-se que o aluno utilizou as incógnitas $x$ e $y$ para representar o valor desconhecido, contudo, deveria utilizar apenas uma incógnita na forma da equação $\mathrm{x}+30=270$ onde $x$ representa o valor do salário anterior, 30 representa $\mathrm{o}$ aumento e 270 representa o salário após o aumento. Logo, percebe-se que o aluno não conseguiu usar as incógnitas e nem montar a equação de forma "correta", devido apresentar dificuldades na tradução do problema para a linguagem algébrica na forma de equação. Ideias de acordo com Lochhesd e Mestre (1995) quando afirmam que muitos alunos possuem dificuldades na resolução de problemas algébricos bastante simples, e isso ocorre devido à falta de compreensão dos enunciados em linguagem natural, do desconhecimento das regras de sintaxe da linguagem algébrica e do estabelecimento de relações incorretas entre as duas linguagens.

Enunciado do teste.

Questão 3: Meu avô e meu pai foram pescar. Eles trouxeram 25 peixes de diversas espécies. Meu avô disse que pescou o quádruplo do número de peixe do meu pai. Quantos peixes cada um pescou?

A seguir, veremos a figura da resolução do aluno P para a $3^{\mathrm{a}}$ questão.

Imagem 4: Resposta do aluno P à questão 3.

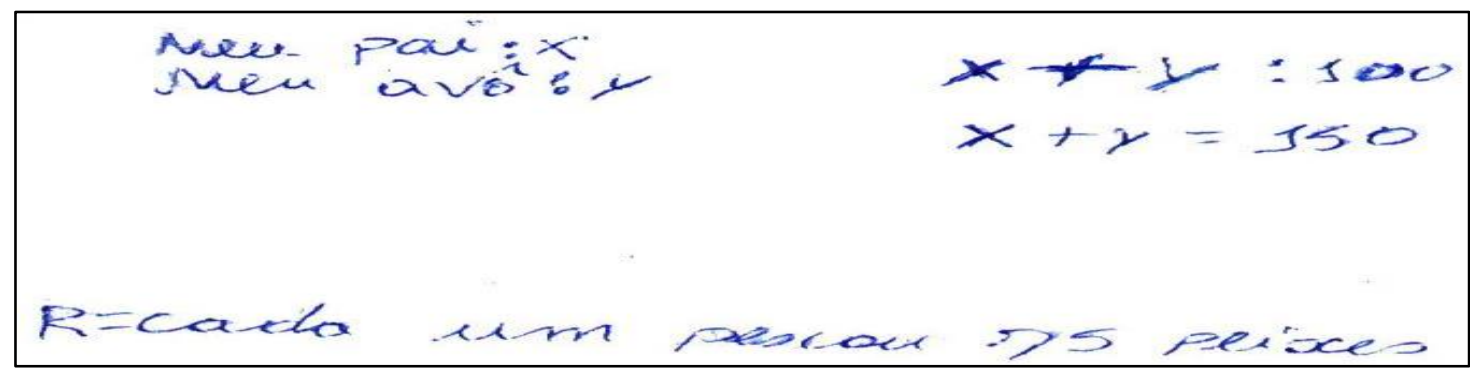

Fonte: Pesquisa de campo / Atividade didática (2012) 
Nesse registro, o aluno deveria ter equacionado o problema da seguinte forma: $4 \mathrm{x}+\mathrm{x}=25$, encontrando o valor de $x$ e em seguida substituindo-o na equação $\mathrm{y}=4 \mathrm{x}$, para encontrar o valor de $y$. No entanto, o aluno não conseguiu equacionar o problema. $\mathrm{O}$ aluno P fez uso das incógnitas $x$ e $y$, que de fato, era necessário estabelecer duas incógnitas para representar os valores desconhecidos, entretanto o mesmo não as utilizou de maneira adequada por não ter interpretado "corretamente" o enunciado da questão, dificultando assim a tradução para a linguagem algébrica ao associar os números com as incógnitas. A resolução apresentada pelo aluno nos faz refletir que o mesmo não tem domínio no uso das incógnitas como instrumento na resolução da questão.

Analisando as questões da categoria 2, concordamos com Gil (2008) quando afirma que a matemática tem uma linguagem própria e uma variedade de símbolos. A autora ao falar desta simbologia na tradução de um problema da linguagem escrita para a linguagem matemática, percebe que uma das barreiras enfrentadas pelos alunos no estudo da Álgebra está na hora de fazer a passagem de uma situação-problema na linguagem corrente para a linguagem algébrica.

\section{Categoria 3: Dificuldades na interpretação dos problemas propostos}

A interpretação dos problemas matemáticos exige do aluno um alto nível de abstração. Entretanto, os alunos apresentam dificuldades na interpretação dos problemas devido o ensino da álgebra ser apresentado de forma mecanizada e sem nenhum significado para o aluno. Segundo os autores pesquisados, isso faz com que os alunos não desenvolvam a capacidade de relacionar o ensino da álgebra com os problemas matemáticos, dificultando a interpretação e tradução destes para a linguagem algébrica. Assim, se compreende que primeiramente o aluno precisa interpretar o problema proposto e posteriormente traduzi-lo da linguagem natural para a linguagem algébrica. Essa categoria foi observada nas questões 3,4 e 5 .

Enunciado do teste.

Questão 3: Meu avô e meu pai foram pescar. Eles trouxeram 25 peixes de diversas espécies. Meu avô disse que pescou o quádruplo do número de peixe do meu pai. Quantos peixes cada um pescou?

A seguir, veremos a figura da resolução do aluno A para a $3^{\mathrm{a}}$ questão. 
Imagem 5: Resposta do aluno A à questão 3.

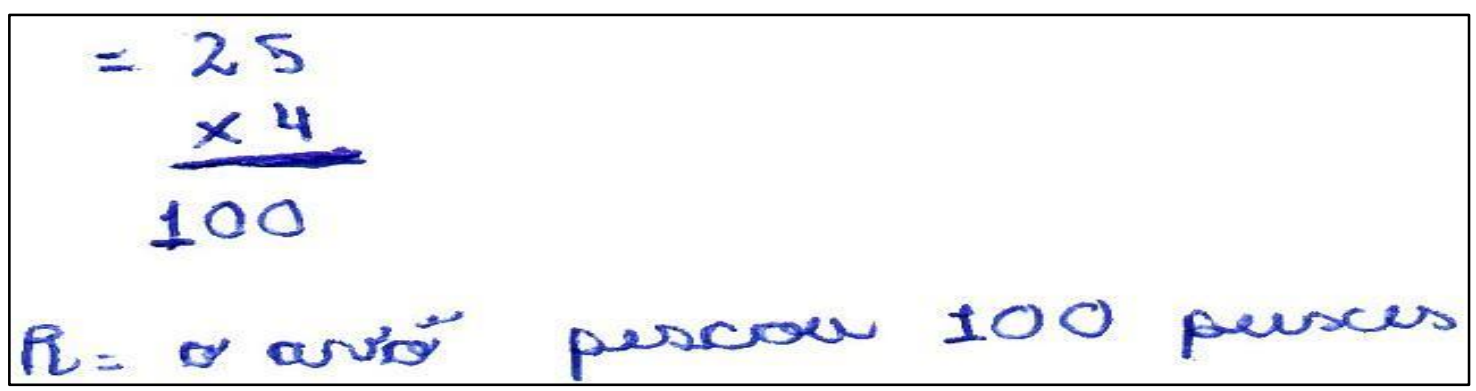

Fonte: Pesquisa de campo / Atividade didática (2012)

Nesse registro, o aluno fez uma interpretação equivocada do enunciado da questão ao multiplicar quatro vezes o número total de peixes. Pois segundo o enunciado da questão, o quadruplo deveria multiplicar o número de peixes que o avô pescou. Sendo assim, o aluno deveria atribuir incógnitas aos valores desconhecidos e equacionar o problema.

Por exemplo, o aluno poderia atribuir as incógnitas $x$ para representar o número de peixes que o pai pescou e y para representar o número de peixes pescado pelo avô. De acordo com o enunciado da questão, o avô pescou o quádruplo do número de peixes que o pai havia pescado, $\log 0 \mathrm{y}=4 \mathrm{x}$, dessa maneira o aluno deveria ter equacionado $\mathrm{o}$ problema da seguinte forma: $4 \mathrm{x}+\mathrm{x}=25$, encontrando o valor de $x$ e em seguida substituindo-o na equação $\mathrm{y}=4 \mathrm{x}$, para encontrar o valor de $y$. Contudo, o aluno não conseguiu interpretar corretamente a questão, logo não traduziu para a linguagem algébrica e não consegui chegar ao resultado "correto".

Sendo assim estamos de acordo com GIL (2008) quando afirma que no estudo de Álgebra, quando o problema matemático envolve uma interpretação exigindo a tradução da linguagem escrita para a linguagem matemática, muitas vezes as dificuldades apresentadas pelos alunos na tradução de situação da linguagem natural para a linguagem algébrica residem na interpretação. Não sendo capaz de interpretar, o aluno não conseguirá representar formalmente a situação.

Enunciado do teste.

Questão 3: Meu avô e meu pai foram pescar. Eles trouxeram 25 peixes de diversas espécies. Мeu avô disse que pescou o quádruplo do número de peixe do meu pai. Quantos peixes cada um pescou?

A seguir, veremos a figura da resolução do aluno W para a $3^{\mathrm{a}}$ questão. 
Imagem 6: Resposta do aluno W à questão 3.

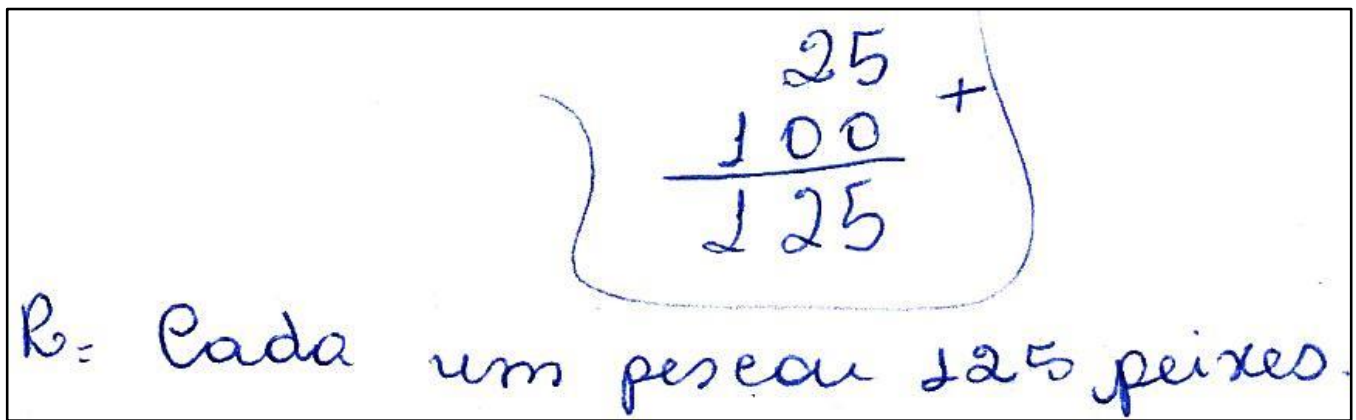

Fonte: Pesquisa de campo / Atividade didática (2012)

No registro acima, o aluno efetuou cálculos aritméticos com dados que organizou de forma errada. Ele somou 25 com o quadruplo de 25, ou seja, $25+100$, obtendo o resultado 125 , valor que não corresponde ao resultado "correto" da questão. Nesse registro, entende-se que a maior dificuldade do aluno foi na interpretação da questão, sendo assim, não traduziu para a linguagem algébrica na forma de equação. Assim como no registro anterior dessa categoria, o aluno não conseguiu interpretar “corretamente", logo não conseguiu resolver a questão.

Enunciado do teste.

Questão 4: A idade de Pedro é metade da de Carlos. A soma das duas idades é 30 anos. Qual a idade de Carlos?

A seguir, veremos a figura da resolução do aluno $M$ para a $4^{\mathrm{a}}$ questão.

Imagem 7: Resposta do aluno M à questão 4.

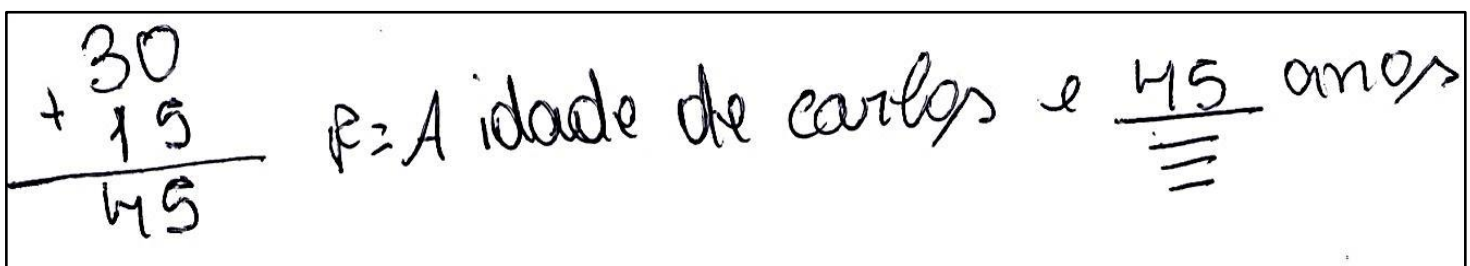

Fonte: Pesquisa de campo / Atividade didática (2012)

Nesse registro, o aluno também interpretou "incorretamente" a questão ao somar 30 (total das idades) com 15 (metade das idades) obtendo o valor 45, resultado "errado". O aluno poderia ter feito uso de duas incógnitas quaisquer para resolver a questão. Por exemplo, $x=$ idade de Pedro, $y=$ idade de Carlos e $30=$ soma das idades. Como a idade de Pedro é metade da idade de Carlos, logo: $\mathrm{x}=\frac{\mathrm{y}}{2}$, de posse dos dados, pode-se organizar na forma da seguinte equação $\frac{\mathrm{y}}{2}+\mathrm{y}=30$. Resolvendo a equação pelo princípio aditivo $\mathrm{e}$ multiplicativo, e, usando a substituição, chega-se ao resultado, onde $\mathrm{x}=10$ e $\mathrm{y}=20$. 
No registro da questão 4, observa-se também dificuldade na interpretação do problema matemático, isso reforça a ideia defendida pelos autores citados nessa pesquisa quando afirmam que as dificuldades dos alunos na tradução de situações dadas em linguagem natural para sistemas de equações são em grande medida idênticas, quando não compreendem os enunciados em linguagem natural e não conseguem estabelecer relações entre as duas linguagens acabam sendo levados ao "erro".

Enunciado do teste.

Questão 4: idade de Pedro é metade da de Carlos. A soma das duas idades é 30 anos. Qual a idade de Carlos?

A seguir, veremos a figura da resolução do aluno B para a $4^{\mathrm{a}}$ questão.

Imagem 8: Resposta do aluno B à questão 4.

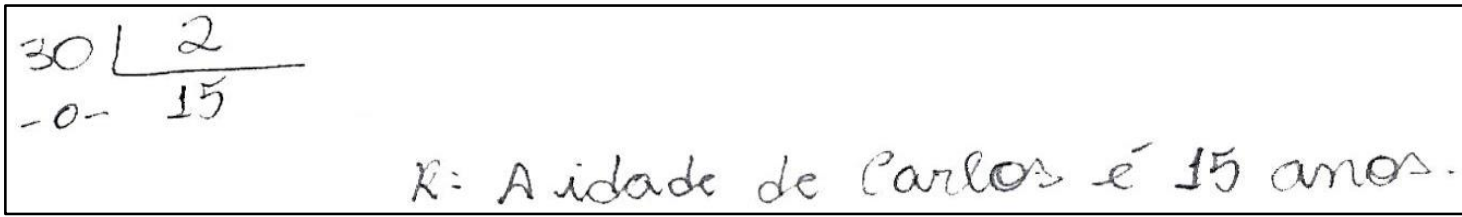

Fonte: Pesquisa de campo / Atividade didática (2012)

No registro acima, acredita-se que o aluno deva ter entendido que a idade de Carlos era de 30 anos, e como a idade de Pedro é metade da idade de Carlos, dividiu 30 por 2, obtendo o valor 15, que não corresponde ao resultado "correto" da questão. Assim como nos registros anteriores dessa categoria, percebe-se que este aluno apresentou dificuldade na interpretação do enunciado da questão, não traduziu para a linguagem algébrica na forma de equação e não consegui resolver a questão.

Enunciado do teste.

Questão 5: Júnior e Luís jogam no mesmo time de futebol de areia. No último campeonato, os dois juntos marcaram 52 gols. Júnior marcou 10 gols a mais que Luís. Quantos gols Júnior marcou nesse campeonato?

A seguir, veremos a figura da resolução do aluno T para a $5^{\mathrm{a}}$ questão.

Imagem 9: Resposta do aluno $T$ à questão 5.

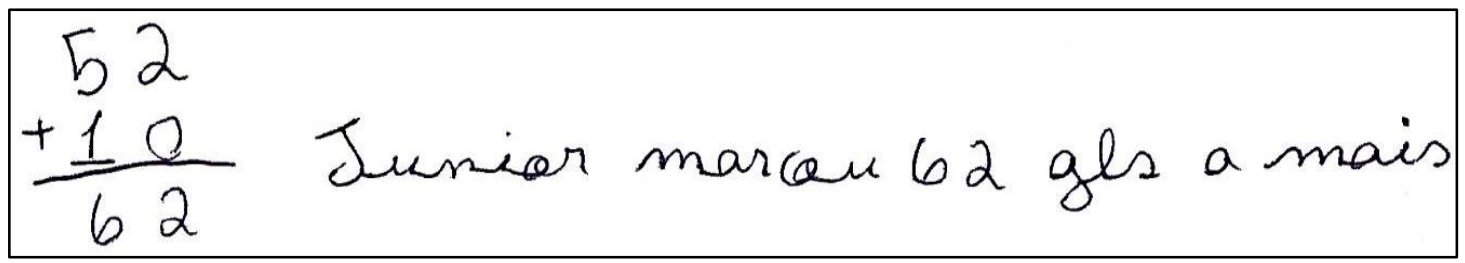

Fonte: Pesquisa de campo / Atividade didática (2012) 
Nesse registro, o aluno apenas utilizou-se dos dados da questão para fazer a soma, ou seja, somou $52+10$, obtendo 62 gols, o que reforça a ideia de que houve equívoco na interpretação. Logo, fica evidente que o aluno apresentou dificuldades na interpretação do enunciado da questão, sendo assim, não traduziu para a linguagem algébrica.

O aluno poderia ter utilizado a incógnita $x$ para representar número de gols que Júnior marcou e y para representar o número de gols que Luís marcou, $\log 0 \mathrm{x}+\mathrm{y}=52$. Como o enunciado da questão afirma que Júnior marcou dez gols a mais que Luís, traduzindo para a linguagem algébrica ficaria representado da seguinte forma: $x=y+10$, e substituindo $(y+10)$ na equação $x+y=52$, o aluno poderia equacionar a questão na forma da equação $(y+10)+y=52$ e em seguida resolvê-la utilizando os princípios aditivo e multiplicativo.

\section{Categoria 4: Dificuldade no cálculo operacional aritmético}

Acredita-se que aritmética seja considerada "mais fácil" que a álgebra, não exigindo do aluno um nível mais elevado de abstração no desenvolvimento do cálculo aritmético. Porém, nessa categoria verificou-se que além dos alunos não traduzirem os problemas para a linguagem algébrica na forma de equação e não utilizarem incógnitas para resolver tais problemas, estes não conseguiram desenvolver o cálculo aritmético apesar de terem interpretado a questão de maneira "correta". Com isso, não chegaram ao resultado "correto" da questão. Essa categoria foi observada nas questões 1 e 2.

Enunciado do teste.

Questão 1: Recebi um aumento de $R \$ 30,00$ e passei a ganhar $R \$ 270,00$. Qual era o meu salário?

A seguir, veremos a figura da resolução do aluno $S$ para a $1^{\text {a }}$ questão.

Imagem 10: Resposta do aluno $S$ à questão 1.

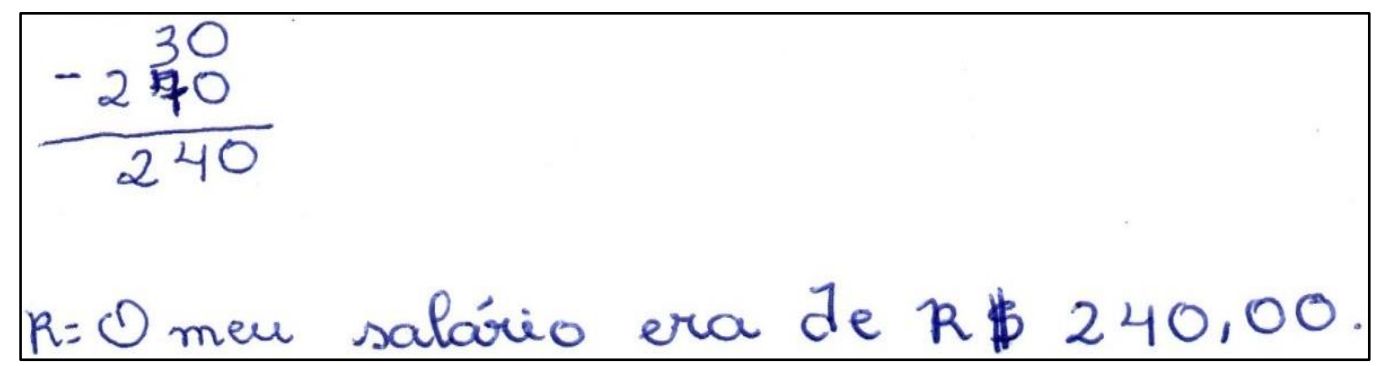

Fonte: Pesquisa de campo / Atividade didática (2012) 
Na situação dada o aluno subtraiu (30 - 270) resultando em (240), com isso, fica evidente um erro no cálculo aritmético, pois se o mesmo tivesse feito a operação da forma como organizou os dados da questão, chegaria a um valor negativo $(-240)$. Com isso percebe-se que esse aluno apresenta dificuldades não apenas na tradução do problema para a linguagem algébrica, mas também no cálculo aritmético.

Neste contexto, estamos de acordo com Gil (2008) quando diz que no momento em que acontece a continuidade entre estes dois campos da Matemática, ou seja, quando os procedimentos aritméticos procedem no contexto algébrico, o aluno traz consigo as dificuldades que já havia na Aritmética.

Enunciado do teste.

Questão 2: Dona Iracema comprou 6 pacotes de detergente em pó e um litro de água sanitária. Ao todo ela gastou 100 reais, sendo que pela água ela pagou 4 reais. Qual o preço de cada pacote de detergente?

A seguir, veremos a figura da resolução do aluno A para a $2^{a}$ questão.

Imagem 11: Resposta do aluno A à questão 2.

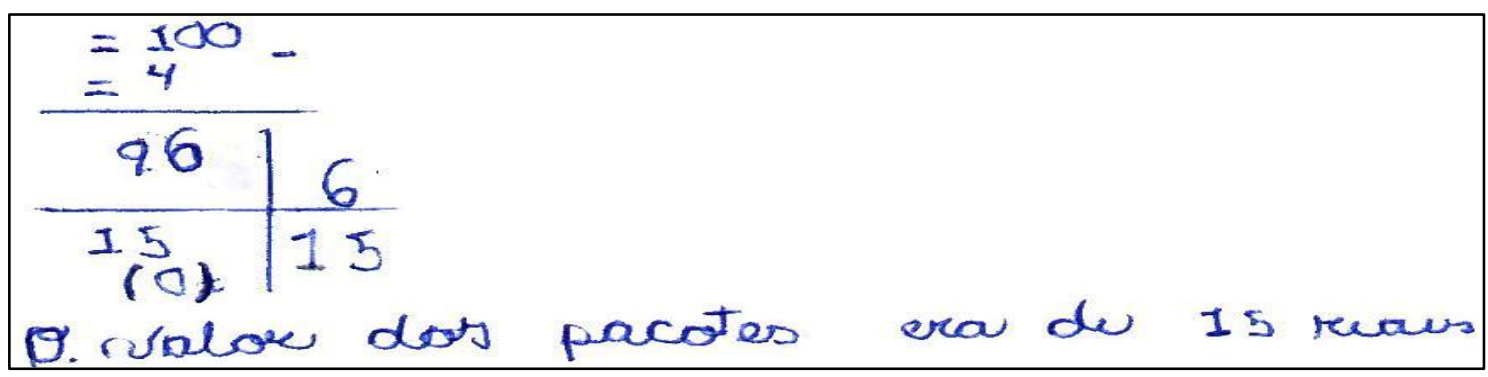

Fonte: Pesquisa de campo / Atividade didática (2012)

Nesse registro, ao desenvolver os cálculos aritméticos, o aluno o fez de maneira equivocada ao dividir 96 por 6 , obtendo o resultado 15 , sendo que o resultado correto dessa divisão é 16, sendo assim o mesmo errou a questão. Com isso, percebe-se que o aluno interpretou de forma "correta" o enunciado da questão, no entanto não traduziu para linguagem algébrica, organizando os dados da questão de forma aritmética, e ainda assim não conseguiu chegar ao resultado "correto" da questão. Sendo assim, observa-se que os alunos apresentam dificuldades não somente na Álgebra, mas também na Aritmética.

\section{CONCLUSÃO}

Os resultados obtidos se assemelham com pesquisas anteriores como Gil (2008) e Lima e Vilhena (2010) que também identificaram as dificuldades relacionadas à 
linguagem algébrica. Gil (2008) fez um estudo sobre a construção do conhecimento através da linguagem algébrica como parte da linguagem matemática e identifica dificuldades relacionadas ao ensino de Álgebra. Lima e Vilhena (2010) fizeram um estudo sobre as dificuldades dos alunos em compreender a linguagem matemática, considerando que o motivo que mais influência na aprendizagem matemática está relacionado com a própria linguagem matemática.

Nessa pesquisa identificou-se as dificuldades enfrentadas pelos alunos na tradução de um problema real da linguagem natural para a linguagem algébrica, assim como as dificuldades no uso de incógnitas para resolver tais problemas. Para tanto foi aplicado um teste aos sujeitos dessa pesquisa constituído de 6 questões, envolvendo equação do $1^{\circ}$ grau. As questões exigiam interpretação do enunciado da questão, tradução das mesmas da linguagem natural para a linguagem algébrica na forma de equação, e por fim, exigiam cálculos aritméticos e algébricos.

Embora alguns alunos utilizaram-se da linguagem algébrica para resolver as questões do teste, observou-se que muitos deles apresentaram dificuldades na tradução da questão para a linguagem algébrica, usando somente cálculo aritmético para resolver as questões, o que se observa em alguns dos registros das 6 questões. Para melhor analisar os registros dos sujeitos dessa pesquisa, as dificuldades que eles apresentaram foram organizadas em quatro categorias: não usaram incógnitas para resolver as questões; dificuldades no uso de incógnitas; dificuldades na interpretação dos problemas propostos; dificuldade no cálculo operacional aritmético.

Na categoria não usaram incógnitas para resolver as questões, percebemos que de fato o aluno apresenta dificuldades em aceitar uma letra como incógnita para representar valores desconhecidos, pois está acostumado a utilizar somente da aritmética para resolver tais problemas. Além disso o aluno não traduziu o problema proposto para a linguagem algébrica na forma de equação, usando apenas a aritmética para resolver a questão.

$\mathrm{Na}$ categoria dificuldades no uso de incógnitas, embora os alunos tenham identificado ser necessário traduzir o problema para a linguagem algébrica, estes não conseguiram fazer uso adequado das incógnitas, pois não associaram corretamente os números com as letras. Inferimos que não chegaram ao resultado "correto" por apresentarem "erro" ao equacionar o problema. 
Na categoria dificuldades na interpretação dos problemas propostos, de fato o aluno apresentou dificuldade de tradução dos problemas da linguagem natural para a linguagem algébrica, tal dificuldade ocorreu por não apresentar um grau de abstração necessário para relacionar o ensino da álgebra com os problemas matemáticos. Sendo assim, alguns alunos não resolveram o problema por apresentarem “erro" na interpretação do enunciado das questões.

Na categoria dificuldade no cálculo operacional aritmético, constatamos que os sujeitos da pesquisa além de não terem traduzido os problemas da linguagem natural para linguagem algébrica, utilizando somente o cálculo aritmético para resolver as questões, ainda assim apresentaram erro, dessa vez no cálculo aritmético.

Diante disso, percebemos que os alunos apresentam muitas dificuldades relacionadas ao ensino da álgebra. Assim, cabe ao aluno desenvolver a abstração por meio de um processo de leitura e escrita em linguagem matemática. Isso fará com que seja capaz de desenvolver um pensamento algébrico e traduzir um problema dado em linguagem natural para a linguagem algébrica, deixando de ser mero reprodutor de pensamentos tradicionais de ensino.

Quanto ao professor de matemática é importante que utilize mediações progressivas entre os significados matemáticos e aqueles que o aluno domina, que busque metodologias que propiciem aos alunos um aprendizado significativo, contribuindo dessa forma para que o ensino da álgebra se torne mais eficiente, e minimizando as dificuldades apresentadas pelos alunos. O ensino da álgebra de forma contextualizada, e utilizando-se de metodologias adequadas, pode ajudar a estruturar o raciocínio do aluno, permitindo que este possa equacionar e resolver problemas de situações do cotidiano. A construção do pensamento algébrico deve iniciar de forma gradativa para que os alunos adquiram a compreensão destes, pois entende-se que este processo é lento e complexo e requer que seja desenvolvido de forma que o aluno compreenda os processos presentes que perpassam pelo conhecimento algébrico.

Os resultados obtidos por meio dessa pesquisa podem servir de base para que os professores possam elaborar propostas de ensino visando minimizar as dificuldades dos alunos em relação ao estudo de equações algébricas. Esperamos que esses escritos possam ser replicado em outros cenários com os professores podendo obter resultados pearecidos e conseguir ajudar seus alunos. Esperamos também que este escrito possa contribuir com novas pesquisas quanto ao desenvolvimento do pensamento algébrico. 


\section{REFERÊNCIAS}

BONJORNO, José Roberto; BONJORNO, Regina Azenha; OLIVARES, Ayrton. Matemática: Coleção fazendo a diferença. $8^{\circ}$ Ano. São Paulo: FTD, 2006.

BRASIL. Ministério da Educação e do Desporto. Parâmetros Curriculares Nacionais: Volume 3. Matemática, Brasília: MEC/SEF, 1997.

DINIZ, Maria Ignez de Souza Vieira. Uma visão do ensino de matemática. In: Temas e Debates, ano IV, n.3, p. 27-30, 1991.

FIORENTINI, D.; LORENZATO, S. Investigações em educação matemática: percursos teóricos e metodológicos. Campinas: Autores Associados, 2006.

GIL, Katia Henn. Reflexões sobre as dificuldades dos alunos na aprendizagem da álgebra. 120f. Dissertação (Mestrado em educação matemática) - PUC-RS, Porto Alegre, 2008. Disponível em: https://repositorio.pucrs.br/dspace/handle/10923/2962. Acesso em set. 2012.

GIOVANNI JÚNIOR, José Ruy, CASTRUCCI, Benedicto. A conquista da matemática: $7^{\circ}$ Ano. São Paulo: FTD, 2009.

LIMA, Waldirley Campos de; VILHENA, Andréa André. A compreensão da linguagem matemática no ensino de Álgebra. Trabalho de Conclusão de Curso - UEPA. Moju, 2010.

LINS, R. C.; GIMENEZ, J. Perspectivas em Aritmética e Álgebra para o Século XXI. 4. ed. Campinas, SP: Papirus, 1997.

LOCHHESD, Jack; MESTRE, José P. Das Palavras à Álgebra: corrigindo concepções erradas. In: COXFORD, Artur F. e SHULTE, Albert P. As ideias da Álgebra. São Paulo: Atual, 1995.

PATRÍCIO, Rafael Silva. As dificuldades relacionadas à aprendizagem do conceito de vetor à luz da teoria dos registros da representação semiótica. Dissertação (mestrado) - Universidade Federal do Pará, Belém, 2010.

PONTE, João Pedro da; BRANCO, Neuza; MATOS, Ana. Álgebra no ensino básico. 2009.

ZUCHI, Ivanete. A importância da linguagem no ensino de matemática. Educação Matemática em Revista. São Paulo: Ano 11, n. 16, p. 49-55, 2004.

Recebido em: 20/11/2021

Aprovado em: 23/12/2021

Publicado em: 27/12/2021 